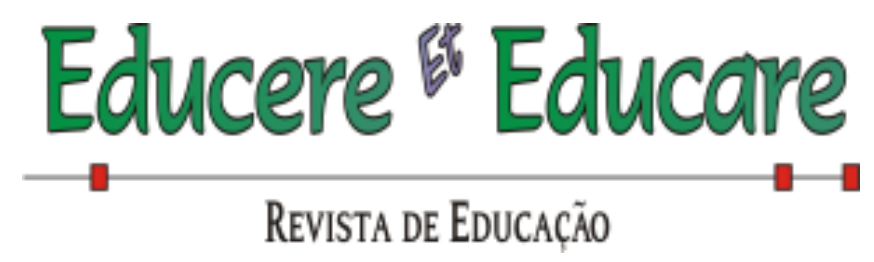

Programa de Pós-Graduação em Educação - Universidade Estadual do Oeste do Paraná

\title{
A AUTONOMIA PERMITIDA PELAS ATIVIDADES PRÁTICAS E/OU INVESTIGATIVAS PRESENTES NOS LIVROS DIDÁTICOS DE CIÊNCIAS DOS ANOS INICIAIS DO ENSINO FUNDAMENTAL
}

\section{Cleuza Machado de Camargo \\ Universidade Estadual de Londrina \\ Dra. Fernanda Franzolin \\ Universidade Federal do ABC}

\begin{abstract}
RESUMO: Este trabalho investigou qual é a autonomia permitida pelos Livros Didáticos do Ensino de Ciências dos Anos Iniciais do Ensino Fundamental aos alunos na realização de atividades práticas e/ou investigativas. A literatura e o Programa Nacional do Livro Didático (PNLD) defendem a inclusão dessas atividades. Quatro coleções aprovadas pelo PNLD foram analisadas para responder as seguintes questões: Quem propõe o que será investigado ou experimentado? Quem propõe a metodologia? Quem coloca a metodologia em
\end{abstract}

\begin{abstract}
prática? O livro apresenta o resultado ao aluno? O Livro apresenta o resultado ao Professor? Quem analisa os dados? Verificouse que a autonomia dada ao aluno, mesmo que parcial, é existente. Foram identificadas atividades nas quais o aluno tem autonomia para também propor a metodologia e, na maioria das coleções analisadas, o livro delega ao aluno a ação de fazer a atividade prática, analisar os dados e chegar ao resultado, podendo ser exploradas pelos professores como propostas de investigação.
\end{abstract}

PALAVRAS-CHAVE: Atividades Práticas e/ou investigativas; Autonomia; Livros Didáticos.

\section{AUTONOMY GIVEN BY PRACTICAL AND/OR INQUIRY ACTIVITIES PRESENT IN SCIENCE TEXTBOOKS USED IN THE EARLY YEARS OF PRIMARY EDUCATION}

\begin{abstract}
This study aims to analyse science textbooks used in the early years of primary education to examine the autonomy they provide to students to conduct practical and/or inquiry activities. Both the literature and the National Textbook Program (Programa Nacional do Livro Didático - PNLD) value the importance of performing practical and inquiry activities and the autonomy of students during their studies. Four collections of books approved by the PNLD were analysed answer the following questions: Who proposes what will be investigated or experimented upon?
\end{abstract}

Who proposes the methodology? Who puts the methodology into practice? Does the textbook present the results to the student? Does the textbook present the results to the teacher? Who analyses the data? It was found that partial autonomy was accorded to students. However, in most collections, the textbook delegates to the student the responsibility of performing practical experiments, analysing data, and arriving at conclusions. They can be explored by teachers to provide inquiry activities.

KEYWORDS: Pratical ad/or Inquiry Activities; Autonomy; Science Textbooks. 


\section{Educere "Educare \\ RevISTA De Educacão}

Programa de Pós-Graduação em Educação - Universidade Estadual do Oeste do Paraná

\section{INTRODUÇÃO}

Este trabalho teve como objetivo investigar a autonomia permitida por propostas de atividades práticas e/ou investigativas encontradas em Livros Didáticos dos Anos Iniciais do Ensino Fundamental, tendo como questões norteadoras: Qual é a participação do aluno em cada etapa da atividade prática/investigativa proposta pelo livro? Os livros propõem diferentes níveis de autonomia ao aluno?

Esta pesquisa se debruça sobre o livro didático devido seu lugar de importância dentro das situações de ensino. É considerado um veículo da divulgação científica, contendo informações, ideias e conceitos (PECHULA, POZZO; BOCANEGRA 2012), favorecendo o acesso ao conhecimento científico construído historicamente pela humanidade e reorganizado enquanto saber escolar (BAGANHA, 2010). Possui vários discursos, o científico, o midiático, o cotidiano e o pedagógico (MARTINS, 2012) e a transposição didática que lhe dá origem não se apoia apenas em conhecimentos, mas também em valores e práticas (CLÉMENT, 2006).

Certamente a crítica relacionada ao uso desse material como um único recurso escolar para nortear o trabalho do professor é pertinente (MEGID NETO E FRACALANZA, 2003). Todavia, os livros didáticos podem ser um dos diversos materiais utilizados pelos professores. Como afirmam os autores, o professor pode utilizá-lo não somente como fonte de textos para leitura complementar e imagens, mas também de exercícios e atividades (MEGID NETO; FRACALANZA, 2003).

Segundo o Guia de livros didáticos PNLD 2013 (Programa Nacional do Livro Didático) (BRASIL, 2012), as coleções de Ciências analisadas nesta pesquisa passaram por avaliação de seus aspectos metodológicos, onde espera-se que a coleção apresente: 


\section{Educere Educare \\ RevISTA DE EducAcão}

Programa de Pós-Graduação em Educação - Universidade Estadual do Oeste do Paraná

[...] propostas de atividades que estimulem a investigação científica, por meio da observação, experimentação, interpretação, análise, discussões dos resultados, síntese, registros, comunicação e de outros procedimentos característicos da Ciência; [...] (BRASIL, 2012, p. 9).

Também foi avaliado se o Manual do Professor: 1) busca valorizar o docente como um problematizador e apresenta orientações para que ele proponha aos alunos novas possibilidades de investigações científicas; e 2) sugere outros tipos de atividades e experimentos, além dos que estão contemplados no Livro do Aluno. Desse modo, o PNLD tem a preocupação de que os livros favoreçam atividades práticas e investigativas. O Guia do PNLD (BRASIL, 2012) ressalta que os autores estão cada vez mais preocupados com a inclusão dessas atividades e também quanto ao grau de liberdade investigativa que elas podem fornecer ao aluno:

O conceito de "ensinar ciência fazendo ciência" tem sido apropriado cada vez mais pelos autores, que têm proposto experimentos interessantes, de "final aberto", que levam a um tipo de investigação característica de uma verdadeira pesquisa científica, à semelhança do que ocorre nos laboratórios das universidades e centros de pesquisa. Entendido como um processo, as coleções deste PNLD 2013 apresentam avanços marcantes no caminho da formação de um aluno com espírito crítico aguçado, curioso sobre as questões da natureza e criativo em busca de soluções. Ainda aparecem experimentos com "final fechado", que são acompanhados de "receitas", bastando ao aluno segui-las para chegar a um resultado já previamente previsto. Entretanto, esses experimentos também têm sua utilidade para o domínio de alguma técnica ou procedimento experimental e para apreensão de certos conteúdos (BRASIL, 2012, p. 7).

Apesar dos professores fazerem poucas atividades experimentais (BUENO, 2017; RAMOS; ROSA, 2008), a literatura também aponta que livros desse nível de ensino oferecem atividades exploratórias, trabalhando a observação do aluno e sua busca pelas respostas (RAMOS; ROSA 2008). Portanto, esta pesquisa buscou verificar como isso vem ocorrendo nos livros didáticos, analisando as atividades e verificando o grau de autonomia permitida aos alunos na realização de tais atividades práticas ou investigativas propostas.

\section{ATIVIDADES PRÁTICAS E INVESTIGATIVAS}

A literatura cita vários procedimentos didáticos para o ensino de Ciências. Katsuno (2008) investigou diversas teses e dissertações na área de Ciências que 


\section{Educere "Educare \\ RevisTa de EduCAç̃o}

Programa de Pós-Graduação em Educação - Universidade Estadual do Oeste do Paraná

tratavam dos métodos e recursos didáticos para o ensino de Ciências nos Anos Iniciais do Ensino Fundamental. Além das tradicionais já existentes, como as aulas expositivas, as leituras e respostas de questionários dos livros didáticos, os autores mencionam outras possibilidades como a utilização de dicionários, jornais, revistas, instrumentos de observação, coleta de dados, desenhos e os experimentos.

Não há um consenso na literatura do conceito de atividades práticas (ANDRADE; MASSABNI, 2011). Não faz parte do escopo deste trabalho problematizar esta definição, o que fazem bem os autores supracitados. Porém a partir da não satisfação pelas concepções por eles encontradas e propostas, consideramos como atividades práticas toda atividade que envolva a ação física e/ou intelectual do aluno. Nesse sentido, o livro didático propõe vários exercícios e atividades que envolvem a prática de aplicação de conhecimentos e seu próprio texto pode propiciar a prática de leitura. Todavia, este trabalho foca sua análise nas atividades práticas que envolvem contato com materiais e com o ambiente, como experimentos, observação e coleta de dados em campo, elaboração de modelos, cultivo e cuidados com seres vivos, entre outras possibilidades.

Para os PCNs (BRASIL, 1997), em Ciências há diversos procedimentos que possibilitam a aprendizagem do aluno, tais como as investigações, a observação direta e indireta, a experimentação, a realização de entrevistas e visitas, entre outros. Sugerem, ainda, que o aluno faça registro das informações coletadas por meio de tabelas, desenhos, quadros, esquemas, gráficos, textos e maquetes.

Destacam também a importância das atividades experimentais nos Anos Iniciais do Ensino Fundamental. Consideram que a prática investigativa e todo o processo de execução contribuem para um aprendizado significativo e despertam no estudante o interesse e a responsabilidade. Os alunos trabalham ativamente na investigação e na execução dos experimentos, tornando-se autônomos e conscientizando-se sobre os fenômenos naturais e sua diversidade (BRASIL, 1997). 


\section{Educere "Educare \\ RevisTa de EduCAç̃o}

Programa de Pós-Graduação em Educação - Universidade Estadual do Oeste do Paraná

Portanto, tais atividades permitem a construção de novos conceitos. Segundo Carvalho $(1997,2013)$ quando os alunos trabalham em equipe com um experimento, o professor está incentivando-os a terem contato físico com o material a ser trabalhado, a verem como funciona, a explorarem os detalhes, a verem as estruturas de tal material. Com isso, passam da ação manipulativa para a ação intelectual e aprendem na relação dialógica com o outro.

Zimmermann (2005) também afirma que as atividades experimentais realizadas em laboratórios ou em sala de aula, servem de abertura para se chegar a novos conhecimentos. Nesse momento, o trabalho em equipe se torna uma situação desafiadora, pois cada componente da equipe tem uma ideia para solucionar o problema. Para chegar a um resultado satisfatório, é necessária muita discussão e, com isso, eles reconstroem seus conhecimentos.

As atividades experimentais podem, portanto, ser investigativas, apesar de atividades investigativas não serem necessariamente sempre atividades experimentais e nem toda atividade experimental ser necessariamente investigativa. De acordo com Zompero e Laburú (2010), atualmente, as atividades investigativas não têm a pretensão de formar cientistas, como acontecia na década de 1960. Elas vêm sendo propostas com outras finalidades, como levar os alunos a desenvolver habilidades cognitivas, argumentação, realização de procedimentos investigativos, elaboração de hipóteses, registro e análise de dados, entre outros. Diferentemente das práticas tradicionais de ensino, através das atividades investigativas o aluno tem a possibilidade de recriar, de relacionarse com os demais e utilizar seus conhecimentos para chegar à resolução do problema proposto. Zanon e Freitas $(2007$, p. 95), defendem que essas atividades envolvam "(...) manipulação de materiais, questionamento, direito ao tateamento e ao erro, observação, expressão e comunicação, verificação das hipóteses levantadas". Ademais mencionam que essas atividades envolvem um trabalho de análise e de síntese, a imaginação e o encantamento pela investigação. 


\section{Educere "Educare \\ RevisTa de EduCAç̃o}

Programa de Pós-Graduação em Educação - Universidade Estadual do Oeste do Paraná

Para Cachapuz et al. (2005) atividades que envolvem a experimentação favorecem a alfabetização científica do aluno. A alfabetização científica presume que os cidadãos devem ter acesso aos princípios básicos das ciências e compreender como esses conhecimentos são gerados, podendo, desta forma, estarem aptos para tomar decisões nas suas vidas e perante a sociedade. $\mathrm{O}$ trabalho com o experimento e a investigação seria uma maneira de mostrar para os alunos como o conhecimento científico é construído, propiciando a alfabetização científica.

O Guia do PNLD (BRASIL, 2012) destaca a elaboração de hipóteses, experimentação e a formulação de explicações como procedimentos básicos utilizados pelos cientistas na investigação dos fenômenos da natureza, procedimentos esses também utilizados pelas crianças quando buscam compreender o mundo, apesar da experimentação em sala de aula não ter a mesma complexidade da realizada pelos cientistas, conforme afirma Bizzo (2007). Dessa forma, o professor estaria ensinando ao aluno que o conhecimento não é algo pronto e acabado cujo resultado já é esperado, mas sim mostrando que, para chegar a um conhecimento científico, existe a origem de um problema e um processo de investigação em evolução, com dificuldades no decorrer de sua execução.

Goldschimidt (2012) lembra que ao trabalhar Ciência, se busca a verdade; no entanto, os resultados científicos obtidos não devem ser considerados como verdade absoluta, pois ela se faz no trabalho coletivo dos cientistas, que eles estão em constante questionamento e insatisfeitos com suas próprias verdades. Para os PCN (BRASIL, 1997), ao propor uma investigação aos alunos, o professor deve incentivá-los a buscar informações em diversas fontes, como jornais, revistas, livros, internet, enciclopédias; com isso, o professor propicia ao aluno a oportunidade de fazer elaborações de suas ideias e suas atitudes perante o problema a ser resolvido e, consequentemente, desenvolver sua autonomia de 


\section{Educere "Educare \\ RevISTA De Educacão}

Programa de Pós-Graduação em Educação - Universidade Estadual do Oeste do Paraná

forma crescente, através de leituras, da observação, experimentação, da manipulação na obtenção do conhecimento.

\section{METODOLOGIA}

Esta publicação é proveniente de um Trabalho de Conclusão de Curso de Pedagogia defendido na Universidade Estadual de Londrina (CAMARGO, 2014), realizado no escopo do projeto de pesquisa "A diversidade de atividades sugeridas pelos livros didáticos para o Ensino de Ciências", sobre a coordenação da segunda autora, grupo de pesquisa GPEnCiBio (Grupo de Pesquisa em Ensino de Ciências e Biologia).

Para investigar o nível de autonomia das atividades práticas e investigativas, nos baseamos em dois autores, Krasilchik (2004) e Bizzo (2007), que apresentam classificações para atividades experimentais no ensino de Ciências, todavia, há também outras propostas similares na literatura. Apesar de os autores não se referirem especificamente aos Anos Iniciais, as classificações apresentadas por eles podem ser atribuídas para qualquer nível de ensino.

Krasilchik (2004) classifica as atividades de acordo com critérios de liberdade concedida aos alunos para executá-las, classificando-as em quatro níveis. Os quatro níveis de classificação vão desde o que permite menor autonomia aos alunos (nível 1), pois é o professor que realiza todos os procedimentos, traz a pergunta e também a resposta, até a um nivel que permite maior participação, pois os alunos têm autonomia de escolher o problema a ser investigado, planejar os procedimentos, formas de execução e de interpretação dos resultados obtidos (nível 4).

Bizzo (2007) também defende a importância de realizar atividades experimentais, classificando-as como experimentos exploratórios ou demonstrativos. Experimento exploratório é aquele de que não se sabe anteriormente exatamente qual resultado será obtido. Portanto, o aluno recebe um problema e tem autonomia para fazer a investigação do mesmo, para chegar a 


\section{Educere "Educare \\ RevISTA De Educacão}

Programa de Pós-Graduação em Educação - Universidade Estadual do Oeste do Paraná

um resultado. Já os experimentos demonstrativos são aqueles realizados para demonstrar um determinado fenômeno e cujo resultado já é sabido a priori.

O trabalho foi pautado na análise de livros didáticos de Ciências dos Anos Iniciais do Ensino Fundamental. A seleção da amostra de livros foi feita a partir do contato com vinte e cinco escolas em 2013, sendo cinco de cada uma das cinco regiões do Brasil, com o propósito de saber qual o nome da coleção de Livros Didáticos de Ciências do Ensino Fundamental dos Anos Inicias adotada pela instituição. As duas primeiras tentativas de contato foram por intermédio de e-mail. Por não obter resposta, a terceira opção foi fazer um levantamento via internet de telefones de escolas e o contato foi por meio de ligação telefônica.

Houve muita dificuldade para conseguir o nome da coleção adotada pelas instituições, pois sempre que alguém atendia, dizia que a pessoa responsável em passar tais informações não se encontrava naquele momento e pedia para retornar depois. Após muitas tentativas obteve-se o nome das coleções adotadas de vinte e cinco escolas. Dentre elas, analisamos duas coleções mais citadas, Porta aberta (GIL; FANIZZI, 2011) e Projeto Buriti (BEZERRA, 2011), e as duas menos citadas Aprender a Aprender (SECCO, 2011) e Agora é Hora (OLIVEIRA, L.; FARIA, 2011).

A análise foi restrita aos livros do $4 .^{\circ}$ ano do Ensino Fundamental. Foi construída uma planilha utilizando o aplicativo Excel, para registro dos dados, da qual foram gerados os gráficos apresentados nos resultados deste artigo. Em cada atividade, foram analisados os seguintes itens: Quem propõe o que será investigado ou experimentado? Quem propõe a metodologia? Quem coloca a metodologia em prática? Quem analisa os dados? O livro apresenta o resultado ao aluno? O livro apresenta o resultado ao professor? Por fim os dados obtidos pela pesquisa foram relacionados com as classificações para atividades práticas e experimentais apresentadas por Krasilchik (2004) e Bizzo (2007). 


\section{Educere "Educare \\ REVISTA DE EdUCACÃ̃o}

Programa de Pós-Graduação em Educação - Universidade Estadual do Oeste do Paraná

\section{RESULTADOS E DISCUSSÃO}

Ao analisar os dados foi constatado que, em todas as coleções analisadas, quem propõe o que será investigado ou experimentado são os livros, como, por exemplo, a abaixo da coleção Aprender a Aprender (2011):

Vamos analisar uma flor com bastante atenção para observar os grãos de pólen (pozinho amarelado das flores).

Você precisa de:

Uma flor com órgãos reprodutores bem evidentes

Pincel

Pinça

Lupa

Como fazer:

1-Observe a flor com auxílio da lupa e do esquema da página 108 para identificar suas partes principais.

2-Encontre grãos de pólen na flor. Com o auxílio da pinça, retire um pouco do pólen e coloque-o sobre uma folha de papel.

3-Espalhe com pincel.

4-No caderno desenhe os grãos vistos pela lupa. Desenhe também os outros tipos de pólen que os colegas coletaram. Mostre seus registros aos colegas e ao professor (APRENDER A APRENDER, 2011, Manual do Professor, p. 111).

Como é também verificar-se no exemplo acima, na maioria das atividades (Grafico 1), o livro propõe a metodologia a ser utilizada, o que pode propiciar a interpretação de protocolos (BRASIL 2007). Porém, em todas as coleções há também a oportunidade de o aluno propor a metodologia, apesar de em número menor de atividades, conforme ilustrado no exemplo a seguir:

\section{Tarefa}

Vamos mergulhar, em um recipiente com água, um copo com um pedaço de papel dentro, sem molhar o papel. O que podemos fazer? Conversem e realizem o experimento quantas vezes forem necessárias. Um colega será o relator, anotará o resultado obtido em cada experimento realizado. Terminando a atividade, o grupo escreverá um texto com a conclusão final a que chegaram (AGORA É HORA, 2011, p. 10). 


\section{Educere "Educare \\ ReVISTA DE EdUCACÃ̃}

Programa de Pós-Graduação em Educação - Universidade Estadual do Oeste do Paraná

Gráfico 1 - Gráfico representando quem propõe a metodologia a ser utilizada

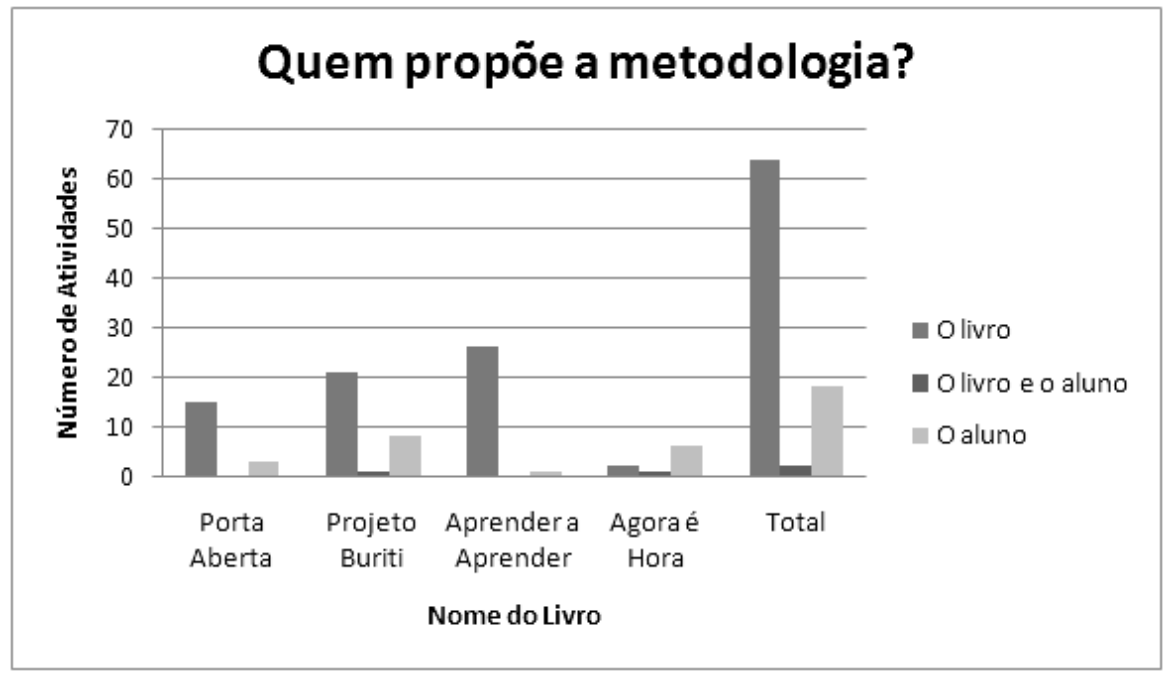

Fonte: autores

Em alguns casos o livro e o aluno concomitantemente propõem a metodologia a ser utilizada, como no exemplo abaixo da coleção Projeto Buriti (2011):

\section{O que você vai fazer}

Testar maneiras de gerar mais movimento em um objeto.

\section{Material}

Uma régua plástica de 39 centímetros

Um apontador

Livros e cadernos

Lápis

\section{Como você vai fazer}

1 Forme grupo com dois ou três colegas.

2 Marquem um ponto fixo na mesa. A mais ou menos um palmo desse ponto fixo, coloquem alguns livros empilhados, até aproximadamente quatro dedos de altura.

3 Coloquem a extremidade da régua com a marca 0 (zero) no ponto fixo da mesa e apoiem a outra extremidade na pilha de livros.

4 Agora, posicionem o apontador na marca de 10 centímetros e deixem-no cair livremente, deslizando sobre a régua. Meçam a distância que ele percorreu na mesa. Depois repitam o procedimento, posicionando o apontador na marca dos 20 centímetros e depois na dos 30 centímetros, meçam a distância percorrida pelo apontador nesses dois casos.

Registrem os resultados observados em uma tabela como a do modelo a seguir. 


\section{Educere "Educare \\ RevisTa de EduCAC̄̃̃o}

Programa de Pós-Graduação em Educação - Universidade Estadual do Oeste do Paraná

\begin{tabular}{|l|l|l|l|}
\hline Marca de largada & $10 \mathrm{~cm}$ & $20 \mathrm{~cm}$ & $30 \mathrm{~cm}$ \\
\hline Distância percorrida & & & \\
\hline
\end{tabular}

1 Sem trocar por uma régua mais comprida nem empurrar o apontador, o que é possivel fazer para que ele tenha energia para ir mais longe? Pense em uma maneira de testar suas hipóteses.

$2 \mathrm{O}$ que fornece a energia para o movimento do apontador em cada situação?

3 Que conclusão é possível tirar desse experimento?

(PROJETO BURITI, 2011, Manual do Professor, p. 122).

A maioria das atividades propõe que o aluno coloque a metodologia em prática. Todavia, conforme gráfico 2 e exemplo a abaixo da coleção Aprender a Aprender (2011), há atividades em que o professor auxilia o aluno a praticar a metodologia:

Gráfico 2 - Gráfico representando quem coloca a metodologia em prática

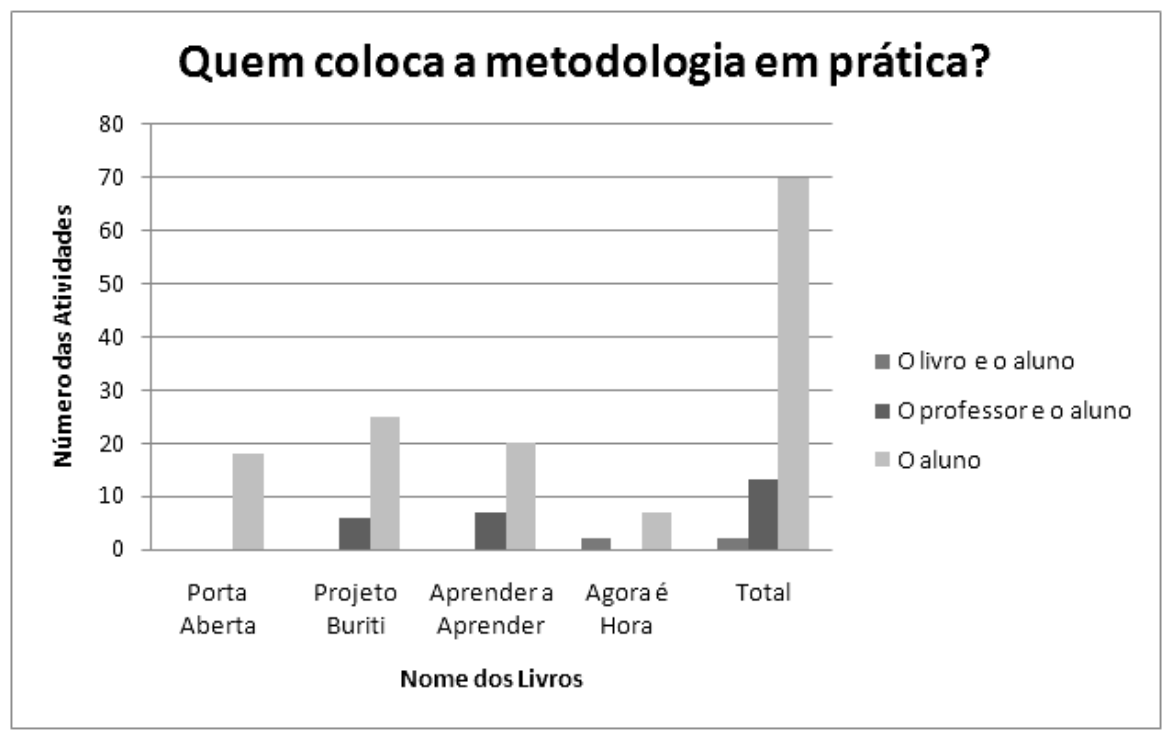

Fonte: autores

\section{Blocos de Notas}

Você precisa de

Caixa de sapato sem tampa

Água fria

Recipiente de vidro com tampa

Papel-aluminio 


\section{Educere "Educare \\ ReVISTA DE EduCACÃo}

Programa de Pós-Graduação em Educação - Universidade Estadual do Oeste do Paraná

Tesoura

Fita adesiva

Termômetro

\section{Como fazer}

Com as orientações do professor e reunido aos colegas de seu grupo, executem o experimento.

1-Revistam o interior da caixa com papel-alumínio. Coloque a parte brilhante para fora.

2-Coloquem a água fria no interior do recipiente de vidro, depois o termômetro, e identifiquem a temperatura.

3-Tampem e posicionem o recipiente dentro da caixa de sapato em local que receba bastante luz solar.

4-Em pouco tempo a água ficará aquecida. Coloquem novamente o termômetro na água e meçam a temperatura.

5-Anotem as temperaturas no início e depois da exposição ao Sol.

a) De quantos graus foi a variação da temperatura da água?

b) Após a explicação do professor, respondam: qual é a importância do papel-alumínio, que reveste a caixa, para o aquecimento da água? (APRENDER A APRENDER, 2011, Manual do Professor, p. 150-151).

Há algumas atividades em que o aluno não coloca a metodologia em prática sozinho, mas o livro também, já apresentando os resultados, como podemos observar no exemplo da coleção Agora é Hora (2011).

\section{Passo a Passo}

1-Vocês são capazes de mergulhar um lenço na água, sem que eles se molhem?

Expliquem no caderno como fariam, ilustrando com um desenho.

Vejam, agora a nossa sugestão para resolver o desafio. Observem bem os desenhos, discutam e dêem a interpretação de vocês. Realizem o experimento e façam um relatório descrevendo tudo que fizeram.

(Em seguida, os autores apresentam uma imagem mostrando uma possível forma de solucionar o problema) (AGORA É HORA, 2011, p. 71-72).

Em todas as coleções, na maioria dos casos é o aluno que analisa os dados das atividades investigativas ou experimentais que realizou (gráfico 5). Entretanto, na coleção Aprender a Aprender há algumas atividades em que se propõe que o aluno analise os dados junto com o professor, conforme demonstra a atividade Blocos de Notas, da coleção Aprender a Aprender (2011), anteriormente citada. 


\section{Educere "Educare \\ ReVISTA DE EduCAC̄̃o}

Programa de Pós-Graduação em Educação - Universidade Estadual do Oeste do Paraná

Já nas coleções Porta Aberta e Projeto Buriti, há algumas atividades em que a análise de dados não é proposta, pois são atividades como construção de modelo ou uso de instrumento, em que o aluno desenvolve a atividade seguindo um roteiro estabelecido pelo livro e ele sabe como a atividade vai ser finalizada, portanto não necessitando fazer a análise.

Gráfico 3 - Gráfico representando quem analisa os dados

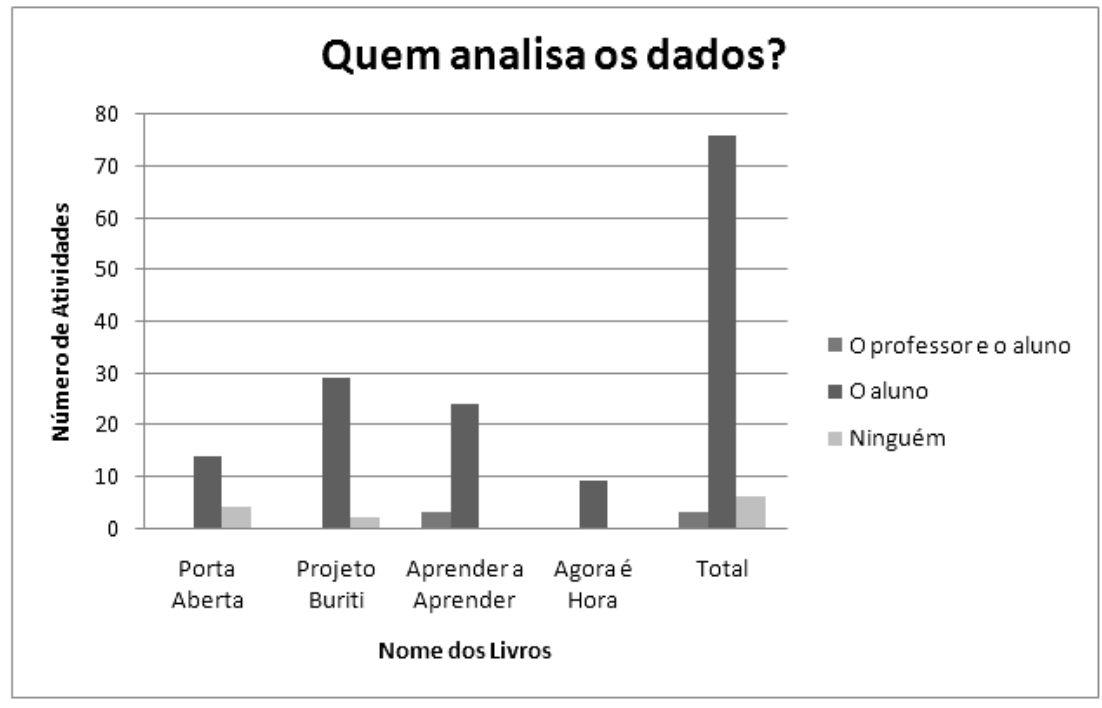

Fonte: autores

Podemos citar como exemplo a atividade Uso de Instrumento da página 13 da coleção Projeto Buriti (2011):

\section{Lupa de Água}

\section{O que você vai fazer}

Construir uma pequena lente de aumento.

\section{Material}

Régua de plástico transparente limpa.

Um copo com água, não é precisa estar cheio.

\section{Como você vai fazer}

1- Apoie a régua sobre uma superficie plana.

2- Molhe a ponta do dedo na água do copo e deixe cair uma gota sobre a ponta da régua.

3- Pronto! Sua lupa já pode ser usada. Com a régua na horizontal, posicione-a sobre algo que queira observar. (PROJETO BURITI, 2011, Manual do Professor, p. 13). 


\section{Educere "Educare \\ ReviSTA De EduCAC̄̃o}

Programa de Pós-Graduação em Educação - Universidade Estadual do Oeste do Paraná

O gráfico 3 demonstra que, nas coleções analisadas, a maioria das atividades não apresenta resultado ao aluno, como, por exemplo nas três primeiras atividades citadas neste artigo. Portanto, na maioria dos casos, o aluno necessita fazer a investigação e a experimentação proposta pelo livro para conseguir concluir a atividade solicitada, sem que o livro the forneça o resultado. Todavia, em alguns casos, o resultado é apresentado. Um exemplo é a atividade Passo a Passo, da coleção Agora é Hora (2011), citada anteriormente.

Gráfico 4 - Gráfico representando se o livro apresenta o resultado ao aluno

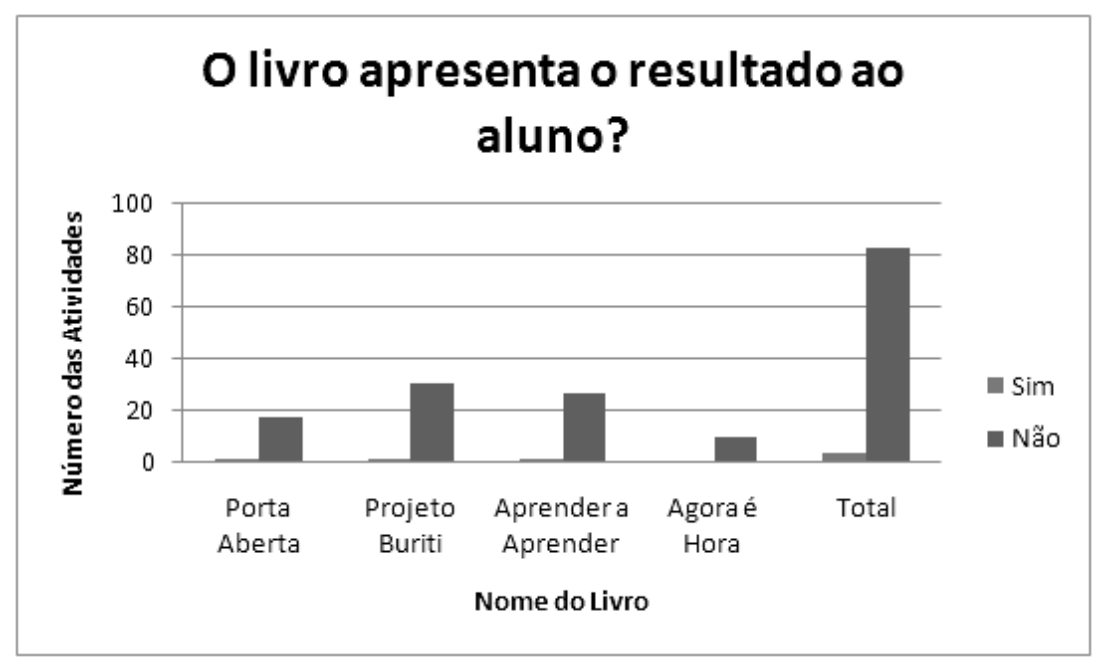

Fonte: autores

No gráfico 4, podemos observar que aproximadamente metade das atividades não apresenta o resultado esperado ao professor. Isso é esperado já que nem todas as atividades possuem um resultado fechado, conforme afirma Bizzo (2007). 


\section{Educere Educare \\ RevISTA De EduCAC̄̃o}

Programa de Pós-Graduação em Educação - Universidade Estadual do Oeste do Paraná

Gráfico 5 - Gráfico representando se o livro apresenta o resultado ao professor

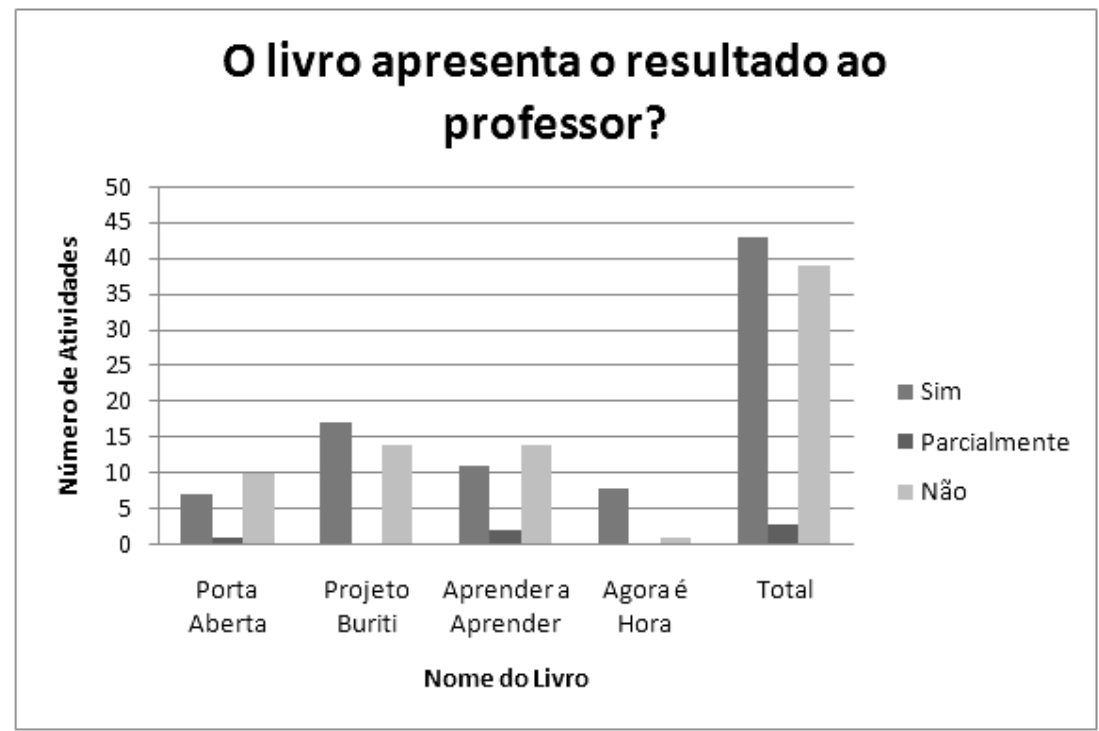

Fonte: autores

Já na outra metade o resultado é apresentado. Isso pode orientar o professor, mas resultados diferentes do esperado não precisam ser vistos enquanto problema, pois a partir dos erros experimentais, inerentes à atividade de investigação, pode se propor outras investigações que procurem a testar variáveis que possivelmente levaram a um resultado diferente do observado, enriquecendo a situação (BRASIL, 1997, BIZZO, 2007). Ademais, o fato de o resultado esperado estar disponivel para o professor, não significa que ele deva já repassá-lo pelo aluno no início da atividade. Deve deixar os alunos coletarem e analisarem seus próprios resultados. Um exemplo de resposta dada para o professor pode ser evidenciado na atividade Em Dupla, da coleção Porta Aberta (2011):

Em dupla

Coloque um balão em um dos cantos de sua mesa escolar. Em seguida, ponha um livro sobre ele, deixando a abertura do balão para o lado de fora da mesa. Peça a seu colega que sopre bem o balão, enchendo-o de ar.

Observe o que aconteceu e descreva oralmente (PORTA ABERTA, 2011, Manual do Professor, p. 58). 


\section{Educere "Educare \\ ReVISTA DE EduCAČ̃̃}

Programa de Pós-Graduação em Educação - Universidade Estadual do Oeste do Paraná

Juntamente, no manual do professor, o livro apresenta o resultado esperado do experimento, para orientá-lo: "O livro será erguido pelo balão. Dependendo do peso do livro e da quantidade de ar, o livro será empurrado, chegando a cair da mesa" (PORTA ABERTA, 2011, Manual do Professor, p. 58).

Na coleção Aprender a Aprender há um exemplo de atividades onde o resultado ao professor é parcial:

\section{Oficina de Estudo}

Algumas pessoas preferem alimentos doces; outras, alimentos salgados, azedos... E você, o que prefere?

a) Recorte de revistas e cole gravuras de alimentos que você gosta, classificando-os conforme o sabor.

\begin{tabular}{|l|l|l|l|}
\hline \multicolumn{4}{|c|}{ Alimentos que aprecio com sabor } \\
\hline Doce & Salgado & Azedo (Ácido) & Amargo \\
\hline & & & \\
\hline
\end{tabular}

b) Podemos comer apenas os alimentos que gostamos? Por quê? Discuta isso com os colegas e o professor e, em seguida, registre a conclusão (APRENDER A APRENDER, 2011, Manual do professor, p. 45).

Juntamente, no manual do professor, o livro apresenta o resultado do experimento: "Sugestões de resposta- Devemos comer alimentos variados, ricos em vitaminas e proteínas. Quem come só aquilo de que gosta corre o risco de adoecer, por ficar malnutrido" (APRENDER A APRENDER, 2011, Manual do Professor, p. 45). Nesse caso, não é possível prever quais serão os resultados da pesquisa dos alunos, apesar de ter um resultado esperado para a questão b.

Cotejando todos os levantamentos acima realizados com a classificação dos diferentes níveis de grau de liberdade de atividades práticas proposta por Krasilchik (2004), foram encontradas poucas atividades do nível 1 (gráfico 6), onde tudo era provido pelo livro, a pergunta, a metodologia e a resposta ao aluno, exatamente devido ao fato de poucas atividades apresentavam uma resposta fechada ao aluno. Esse fato não é negativo, pois como afirma a autora, esse é o nivel mais diretivo. Podem ser considerados experimentos que se encaixam na 


\section{Educere Educare \\ RevISTA DE EducAcão}

Programa de Pós-Graduação em Educação - Universidade Estadual do Oeste do Paraná

classificação de Bizzo (2007) como demonstrativos, por já terem uma resposta esperada no início da realização da atividade, e por seu propósito ser comprovar a ocorrência de um determinado fenômeno, o que nem sempre ocorre, pois os erros são inerentes às experimentações.

Gráfico 6 - Classificação das atividades por nível de liberdade, segundo Krasilchik (2004).

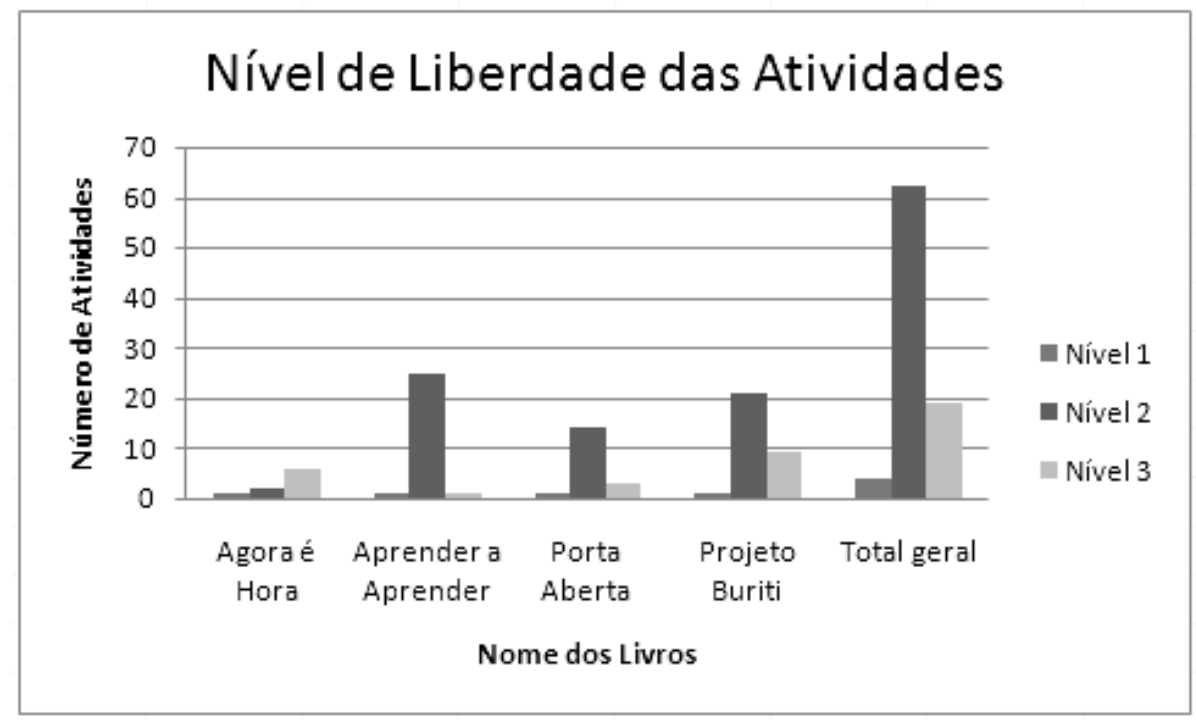

Fonte: autores

Todavia, na literatura, há diferentes concepções de experimento demonstrativo. A definição de demonstrações de Krasilchik (2004) se difere da concepção de Bizzo (2007), pois está centrada na execução da atividade pelo professor. Nos livros analisados não foram encontradas atividades dessa natureza. Essas demonstrações podem ser úteis quando realizadas por professores em atividades que envolvam materiais perigosos ou na falta de materiais para todos os alunos (BRASIL, 1997, KRASILCHIK, 2004). Chiappetta e Koballa (2010) aproximam-se de Krasilchik (2004), quanto colocam o professor como executor da demonstração e se distanciam de Bizzo (2007), pois consideram a possibilidade desses experimentos serem abertos explorando a observação dos alunos a partir de discussões para que eles cheguem à interpretação dos dados observados e a uma resposta, que não necessariamente é fechada. Nessa pesquisa também não foram identificadas atividades com estas características, 


\section{Educere "Educare \\ RevisTa de EduCAç̃o}

Programa de Pós-Graduação em Educação - Universidade Estadual do Oeste do Paraná

pois nenhuma era proposta para ser realizada somente pelo professor. Em sintese, mais importante do que a definição está a constatação de que há diferentes formas de se realizar experimentação, com diferentes níveis de autonomia ao aluno e aplicáveis a diferentes possíveis finalidades.

Contudo, as atividades analisadas que não tinham respostas abertas, em sua maioria eram construções, como, por exemplo, a atividade da lupa de água anteriormente citada. Nestas que o livro fornece a metodologia e o resultado, cabendo ao aluno seguir o passo-a-passo para realização da atividade, consequentemente não necessitando de fazer investigação e analisar o resultado.

Por outro lado, como na maioria das atividades o aluno precisa investigar o problema para chegar ao seu próprio resultado, a maior ênfase dos livros analisados é em atividades que se enquadram na classificação de Bizzo (2007) de experimento exploratório, já que não se sabe anteriormente qual resultado será obtido. Esse tipo de atividade possibilita ao aluno fazer a investigação para chegar ao próprio resultado e o faz vivenciar procedimentos semelhantes a uma investigação científica. Distanciando-se da visão de que a experimentação tem uma resposta certa, o aluno tem a possibilidade de compreender como é produzido o conhecimento científico, algo importante para a sua Alfabetização Científica (CACHAPUZ, et al., 2005). A maioria das atividades, portanto, foi classificada no nível 2 apresentado por Krasilchik (2004), no qual os alunos recebem a pergunta juntamente com os procedimentos a serem investigados, mas buscam seus próprios resultados.

Apesar de não ocorrer em maior frequência, todas as coleções analisadas trazem alguma atividade em que delegam ao aluno a autonomia de propor a metodologia para a investigação. Tais atividades enquadram-se no nivel 3 de autonomia mencionado por Krasilchik (2004), onde o aluno recebe o problema proposto a ser investigado, cabendo a ele a responsabilidade de escolher como proceder para executá-lo e interpretar o resultado obtido, o que desenvolve a autonomia do aluno de procurar estratégias de investigação e testá-las. 


\section{Educere "Educare \\ RevISTA De Educacão}

Programa de Pós-Graduação em Educação - Universidade Estadual do Oeste do Paraná

No quarto nível, Krasilchik (2004) relata que os alunos têm autonomia de escolher o problema a ser investigado, planejar os procedimentos, formas de execução e de interpretação dos resultados obtidos; portanto, o aluno tem maior autonomia para fazer escolhas do problema que pretende investigar. Esse nivel não se encaixa em nenhuma das atividades analisadas. Podemos constatar que em todas as coleções analisadas quem propõe o que será investigado ou experimentado são os livros e em nenhuma atividade proposta o aluno teve autonomia de escolher o que seria investigado, cabendo a ele executar o problema proposto pelo livro. Isso é de certa forma compreensível, já que dos autores de livros é esperada alguma proposta. Todavia é possivel que o professor trabalhe com esse nível com seus alunos em outras situações ou que o próprio livro sugira que os alunos elaborem questões de investigação dentro de alguma temática.

\section{CONSIDERAÇÕES FINAIS}

Este trabalho, ao investigar nos livros didáticos de Ciências dos Anos Iniciais do Ensino Fundamental a autonomia permitida nas propostas de atividades práticas ou investigativas, conclui que todas as coleções permitem certa autonomia para os alunos na realização do problema proposto. Mesmo que, na maioria das atividades, essa autonomia seja parcial, ela é existente, havendo variações no grau de liberdade permitido ao aluno. A literatura aponta a dificuldade da realização de atividades com o grau máximo de autonomia (ZÔMPERO; LABURÚ, 2011), sendo então difícil se restringir a elas, e salienta que ao longo da formação do aluno são importantes atividades com vários níveis de autonomia (KRASILCHIK, 2004).

Em todas as atividades encontradas, são os livros que propõem as questões a serem desenvolvidas pelo aluno, não possibilitando que ele problematize e escolha uma questão do seu interesse para investigar. É possível que seja um desafio incluir atividades em que os alunos tenham liberdade de escolher o 


\section{Educere "Educare \\ RevISTA De Educacão}

Programa de Pós-Graduação em Educação - Universidade Estadual do Oeste do Paraná

problema a ser investigado enquanto uma comanda em livro didático, apesar de haver a possibilidade de o autor convidar os alunos a elaborarem questões de investigação em torno de um tema. Todavia, talvez seja mais propício este tipo de atividade surgir nas situações cotidianas de sala de aula, onde o professor precisará estar atento aos questionamentos e interesses dos alunos para explorar suas curiosidades com investigações. Também ficou evidente que na maioria das atividades, quem indica a metodologia a qual o aluno vai seguir para realização da atividade proposta é o próprio livro. Todavia, todas as coleções analisadas já possuem a preocupação de deixar o aluno propor a metodologia em alguns momentos, apesar de atividades desse tipo serem menos frequentes.

Outro sinalizador do favorecimento da autonomia do aluno é que, em todas as coleções analisadas, na maioria das vezes o livro delega ao aluno a responsabilidade de colocar a metodologia em prática, analisar os dados e chegar aos resultados, fazendo com que ele participe ativamente de todas as atividades propostas, para conseguir chegar ao resultado. Portanto, ficou evidente que há mais atividades exploratórias, nas quais o aluno participa ativamente na resolução do problema proposto agindo com mais autonomia.

Estes dados vão ao encontro dos resultados de Ramos e Rosa (2008), que também encontraram atividades exploratórias nos livros didáticos. Também se aproximam da afirmação do Guia do PNLD (BRASIL, 2012), sobre o fato dos autores estarem cada vez mais preocupados em incluir essas atividades nos Livros Didáticos, favorecendo um maior grau de liberdade na investigação ao aluno, apesar de este poder ainda ampliado.

Dessa forma, foi possivel perceber que em algum grau, a maioria das atividades favorece a participação ativa do aluno. São atividades que em sua grande maioria vão além da simples demonstração, e exploram a capacidade dos alunos em buscar e analisar respostas para problemas a partir de uma investigação. Desta forma, os professes podem aproveitar estas atividades em suas aulas, indo além do uso do livro didático como portador de texto. Partindo 


\section{Educere Educare \\ ReVISTA de EduCAC̄̃̃o}

Programa de Pós-Graduação em Educação - Universidade Estadual do Oeste do Paraná

dessas atividades, gradativamente os professores podem ampliar o grau de autonomia. Vendo que seus alunos já dominam alguns procedimentos, podem solicitar aos poucos que eles próprios criem as metodologias para a resolução das atividades. Ademais, vendo a curiosidade de seus alunos, podem explorá-las com novas investigações, cujo problema parte do questionamento das próprias crianças. Cursos de formação inicial e continuada podem auxiliá-los a pensar nestas possibilidades.

Em suma, concluímos que é possivel partir das propostas apresentadas pelos livros didáticos recebidos pelas escolas para trabalhar a autonomia dos alunos nas investigações e gradativamente ampliar o desenvolvimento dessa capacidade com propostas que vão além desse material. 


\section{Educere "Educare \\ ReVISTA DE EduCACÃo}

Programa de Pós-Graduação em Educação - Universidade Estadual do Oeste do Paraná

\section{REFERÊNCIAS:}

ANDRADE, M. ; MASSABNI, V. Ciência \& Educação, v. 17, n. 4, p. 835-854, 2011

BAGANHA, D. O papel e o uso do livro didático de ciências nos anos finais do ensino fundamental. 2010. Dissertação (Mestrado) - Universidade Federal do Paraná, Curitiba.

BUENO, K. A utilização de recursos, procedimentos e espaços escolares nas aulas de Ciências Naturais dos Anos Inicias do Ensino Fundamental. 2017. Dissertação (Mestrado) - Universidade Federal do ABC, Santo André.

BEZERRA, L. (Org.) Coleção Projeto Buriti: Ciências $4^{\circ}$ ano: Ensino Fundamental. 2. ed. São Paulo: Moderna, 2011.

BIZZO, N. Ciências: Fácil ou difícil? 2. ed. São Paulo: Ática, 2007.

BRASIL. Ministério da Educação / Secretaria de Educação Fundamental. Parâmetros curriculares nacionais: ciências naturais / Secretaria de Educação Fundamental. - Brasília: 1997.

BRASIL. Ministério da Educação, Secretaria de Educação Básica. Guia de Livros Didáticos PNLD 2013: Ciências. Brasilia: Ministério da Educação, Secretaria de Educação Básica, 2012.

CACHAPUZ, A. et al. A Necessária Renovação do Ensino das Ciências. São Paulo: Cortez, 2005.

CLÉMENT, P. Didactic Transposition and KVP Model: Conceptions as Interactions Between Scientific knowledge, Values and Social Practices. ESERA Summer School. Braga: Universidade do Minho, 2006, p. 9-18.

CARVAlHO, A. M. P. Ciências no ensino fundamental. Cadernos de Pesquisa (Fundação Carlos Chagas), São Paulo, p. 152-168, 1997.

CARVALHO, A. M. P. Ensino de Ciências por investigação: Condições para implementação em sala de aula. Cengage Learning: São Paulo, 2013.

CHIAPPETA, L.; KOBALLA Jr., T. Science Instruction in the Middle and Secondary Schools. Boston: Allyn \& Bacon, 2010

GIL, Â. B. de A.; FANIZZI, S. Coleção Porta Aberta: ciências $4^{\circ}$ ano: Ensino fundamental. 1. ed. São Paulo: FTD, 2011. 


\section{Educere "Educare \\ ReVISTA DE EduCACÃo}

Programa de Pós-Graduação em Educação - Universidade Estadual do Oeste do Paraná

GOLDSCHIMIDT, A. I. O ensino de Ciências nos Anos Iniciais: Sinalizando Possibilidades de Mudanças. 2012. Tese (Doutorado) - Universidade Federal de Santa Maria, Santa Maria-RS, 2012.

KATSUNO, A. Métodos e recursos didáticos para o ensino de ciências nas séries iniciais: um estudo de teses e dissertações entre 1997 e 2006. 2008. Trabalho de conclusão de curso (Graduação) - Universidade Estadual de Campinas, Campinas.

KRASILCHIK, M. Práticas de ensino de biologia. 4. ed. São Paulo: Editora da Universidade de São Paulo, 2004.

MARTINS, I. O livro didático de Ciências: contextos de exigência, critérios de seleção, práticas de leitura e uso em sala de aula. Rio de Janeiro: [s.n.], 2012.

MEGID NETO, J.; FRACALANZA, H. O livro didático de ciências: problemas e soluções. Ciência e Educação, v. 9, n. 2, p. 147-157, 2003.

OLIVEIRA, L.; FARIA, M. Coleção Agora é Hora: ciências, $4^{\circ}$ ano: Ensino fundamental. 1. ed. Curitiba, PR: Base Editorial, 2011.

PECHULA, M.; DEL POZZO, L.; BOCANEGRA, C. Considerações sobre o ensino de ciências e o uso de materiais didáticos midiáticos: possibilidades e limites. Contrapontos (Online), v. 12, p. 145-153, 2012.

RAMOS, L. B.; ROSA, P.R.S. O ensino de Ciências: fatores intrínsecos e extrínsecos que limitam a realização de atividades experimentais pelo professor dos Anos Iniciais do Ensino Fundamental. Investigações em Ensino de Ciências, v.13, n.3, p. 299-331, 2008.

SECCO, L. (Ed.). Coleção Aprender a Aprender: Ciências $4^{\circ}$ ano: Ensino Fundamental. 1. ed. São Paulo: Editora PD. 2011.

ZIMMERMANN, L. A importância de ciências para alunos da terceira série do ensino fundamental. 2005. Dissertação (Mestrado em Educação) - Faculdade de Educação, Pontifícia Universidade Católica do Rio Grande do Sul, Porto Alegre.

ZÔMPERO, A. F.; LABURÚ, C. E. As atividades de investigação no Ensino de Ciências na perspectiva da teoria da Aprendizagem Significativa. Rev. electrón. investig. educ. cienc., v. 5, n. 2, 2010. 


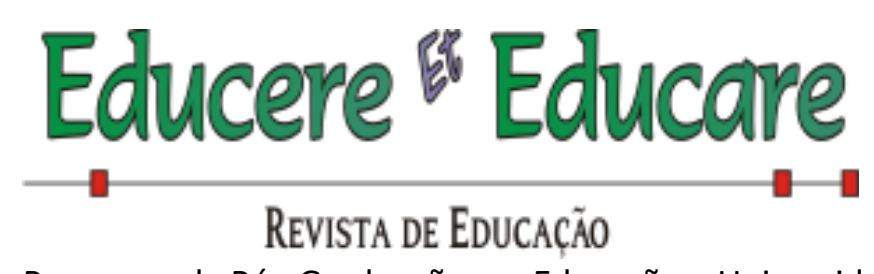

Programa de Pós-Graduação em Educação - Universidade Estadual do Oeste do Paraná

ZÔMPERO, A. F.; LABURÚ, C. E. Atividades Investigativas no Ensino de Ciências: aspectos históricos e diferentes abordagens. Ensaio Pesquisa em Educação em Ciências, v.13, n.3, p. 6.

Recebido em: 20/12/2017 Aprovado em: 21/03/2018 